\title{
Shoreline vegetation distribution in relation to wave exposure and bay characteristics in a tropical great lake, Lake Victoria
}

\author{
Nicholas Azza*1 , Johan van de Koppel $\dagger$, Patrick Denny $\ddagger$ and Frank Kansiime $\S$ \\ * Department of Water Resources Management, Uganda \\ $\dagger$ Centre for Estuarine and Marine Ecology, Netherlands Centre for Ecology, Yerseke, The Netherlands \\ $\ddagger$ UNESCO-IHE Institute for Water Education, Delft, The Netherlands \\ $\S$ Makerere University, Institute of Environment and Natural Resources, Kampala, Uganda \\ (Accepted 4 March 2007)
}

\begin{abstract}
We investigated the presumption that wind-wave exposure is a major regulator of vegetation distribution within lakes. Along a 675-km stretch of shore in northern Lake Victoria (Uganda), the pattern of vegetation distribution in relation to shoreline features, and the variation of shoreline swamp area along a gradient of wave exposure were examined. The ability of wave exposure, when combined with bay morphometric characteristics, to predict the lakeward limit of vegetation distribution was assessed. Data were collected through a shoreline survey and from maps. Maximum effective fetch, computed from topographic maps, was used as a surrogate for wave exposure. Our results reinforce and amplify the notion that wave exposure is an important regulator of the within-lake distribution of vegetation. We found shoreline plants to either occupy stretches of shore shielded by coastal islands or hidden by convolutions of the lake margin. The area of shoreline swamps declined exponentially with increasing wave exposure. Of the coastal characteristics examined, bay area had the strongest influence on the lakeward expansion of vegetation. Wave exposure acting together with bay area, accounted for $64.4 \%$ of the variance in the limit of lakeward vegetation advancement.
\end{abstract}

Key Words: disturbance, environmental gradients, shoreline morphometric features, shoreline plants, tropical swamps, wave action

\section{INTRODUCTION}

Shoreline plants have a major influence on the ecosystem functioning of water bodies they fringe (Carpenter 1983). Their distribution in lakes is regulated by numerous environmental factors and by competition from neighbours (Hutchinson 1975, Keddy 2000, Pearsall 1920, Spence 1982). Wave exposure is one of the environmental factors with a strong influence on shoreline vegetation distribution. It affects vegetation directly by uncovering seeds, uprooting seedlings and damaging mature plants, and indirectly by producing coarser, nutrientdeficient substrates, or burying established plants (Coops et al. 1991, Foote \& Kadlec 1988, Keddy 1982, Kennedy \& Bruno 2000, Riis \& Hawes 2003). Through the above effects, wave exposure produces distinct patterning in shoreline vegetation, with upwind coasts having denser growths of vegetation than downwind

\footnotetext{
${ }^{1}$ Corresponding author. Email: azza.wrmd@dwd.co.ug
}

coasts (Hutchinson 1975, Pearsall 1920, Spence 1982). Wave exposure also limits the lakeward advance (extension of vegetation from the shoreline towards deep, open water) of shoreline vegetation (Keddy 1983).

The quantitative impact of wave exposure on tropical shoreline vegetation is one area where knowledge is limited. Current knowledge of the influence of wave exposure is derived mainly from middle and higher latitudes, which in many cases is unquestionably applicable to tropical lakes (Denny 1985a). Some disparity, nevertheless, must be expected due to differences between the middle and higher latitudes and the tropics. In the inner tropics, for example, plant recruitment and growth occur all year at high rates. This may allow faster recovery of plants damaged during seasonal wind perturbations so that in the long term, the influence of wind and waves is less clearly manifest. Early studies on the influence of wave exposure on the littoral vegetation of tropical lakes, such as Denny (1973), were largely qualitative although it was recognized that the dynamics of exposed and sheltered 
shores supported different vegetation. Little consideration has also been given to the possible influence of embayment characteristics on vegetation distribution. Recent studies that have examined the effect of shoreline morphometric features on vegetation distribution have mainly addressed water depth and/or littoral slope (Chambers 1987, Coops et al. 1994, Duarte \& Kalff 1986, Hudon et al. 2000, Riis \& Hawes 2003). Considering that the shape of a water body affects the way in which waves are generated (CERC 1984, Maas et al. 1997), bays of certain shapes, sizes or aspect ratios may be expected to be better than others at moderating or amplifying the impacts of wind and waves and hence could have greater or lesser influence on vegetation distribution.

In this study we tested the hypothesis that the distribution of vegetation along the shores of a tropical great lake, Lake Victoria, is controlled by wind and wave exposure. We (1) examined the qualitative pattern of shoreline vegetation distribution and compared wave exposure in vegetated and non-vegetated parts of the shore; (2) investigated the variation of shoreline vegetation along a gradient of wave exposure; and (3) assessed how well wave exposure, acting in concert with coastal morphometric characteristics, was able to predict the lakeward limit of vegetation.

\section{STUDY SITE}

Lake Victoria, in East Africa, is the second largest freshwater lake in the world. The lake has a saucer-shaped basin with a surface area of $68870 \mathrm{~km}^{2}$, maximum depth of $84 \mathrm{~m}$ and mean depth of $40 \mathrm{~m}$ (Crul 1998). The level of the lake is unregulated although its outflow (the Nile) was dammed in 1954. Water releases from the dam follow the rating curve of the river before damming. The lake margins are convoluted giving rise to numerous shallow bays fringed in many parts by large tropical swamps. A swamp according to Howard-Williams \& Gaudet (1985) is a boggy, seasonally or permanently flooded area with dense growths of tall herbaceous hydrophytes. Swamp vegetation may be bottom-rooted or anchored in floating root mats (Denny 1993).

The shoreline swamps of Lake Victoria are dominated by the emergent sedge Cyperus papyrus L. and grass Miscanthidium violaceum (K. Schum.) Robyns, which grow in association with shrubs and trees; climbing, creeping and scrambling herbs; ferns; and mosses. The lakeward edges of the swamps are fringed by Vossia cuspidata (Roxb.) Griff., an emergent grass, and a community of euhydrophytes (a collective word for submerged, floating-leaved and bottom-rooted aquatic macrophytes; Denny 1985c) dominated by Nymphaea lotus L., N. heudelotii Planch., N . caerulea Sav., Trapa natans L., Brasenia peltata F. Pursh and Nymphoides nilotica (Kotschy \& Peyr.) Léonard. An understorey typically comprised of single or mixed communities of Ottelia ulvifolia (Planch.) Walp., Ceratophyllum dermer- sum L., Utricularia thonningii Schum., U. foliosa L., Vallisneria spiralis L., Potamogeton schweinfurthii A. Benn. and P. thunbergii Cham. \& Schlecht. is usually present. Surfacefloating plants including Pistia stratiotes L. and Eichhornia crassipes (Mart.) Solms-Laub. may fringe the emergents and, if in profusion, shade out the euhydrophytes.

While swamp vegetation is a dominant feature of the lake's shoreline accounting for over 95\% of vegetated area, some margins have no swamps but feature other shoreline plants, mainly the reed Phragmites mauritianus Kunth, the leguminous shrub Sesbania sesban L. and the rhizomatous, low-growing perennial grass Panicum subalbidum Kunth. More detailed descriptions of the shoreline vegetation can be obtained from Lind \& Morrison (1974) and Denny (1985b). Lake Victoria is fresh, alkaline and eutrophic (LVEMP 2002).

The study was conducted in the Ugandan part of the lake on a $675-\mathrm{km}$ stretch of shore between Goma and Berkeley bays (Figure 1). This stretch is positioned downwind of prevailing southerly winds and has convoluted as well as straight margins, sheltered and exposed shores, a sprinkling of coastal archipelagos and fringing swamps of varying sizes.

\section{METHODS}

\section{Determination of exposure to wind-induced wave action}

Maximum effective fetch was used as the surrogate of wave exposure and was calculated from 1:50000 topographical map sheets (series Y732 of Uganda) using the formula (CERC 1984, Håkanson \& Jansson 1983)

$$
E_{f}=\frac{\sum x_{i} \cdot \cos a_{i}}{\sum \cos a_{i}}
$$

where $E_{f}(\mathrm{~km})$ is the effective fetch (i.e. the open water distance over which wind-induced waves build), $x_{i}(\mathrm{~km})$ is the fetch length or straight-line distance from the point of fetch measurement to land or an island, and $a_{i}$ (degrees) is the angle from the wind-direction azimuth in $6^{\circ}$ increments from $+42^{\circ}$ to $-42^{\circ}$. Maximum effective fetch is the outcome of equation 1 when the wind-direction azimuth is oriented in such a way as to give the longest possible straight-line distance from a measurement point to land or island. Using maximum effective fetch instead of effective fetch in the direction of prevailing winds captures the largest potential wind and wave disturbance events in a site. Storms occur frequently on Lake Victoria and are associated with stronger wind and wave action than prevailing winds. During the storms, winds are of variable direction.

\section{Vegetation distribution along the shore}

To determine the qualitative pattern of shoreline vegetation distribution, a map of the shoreline was 


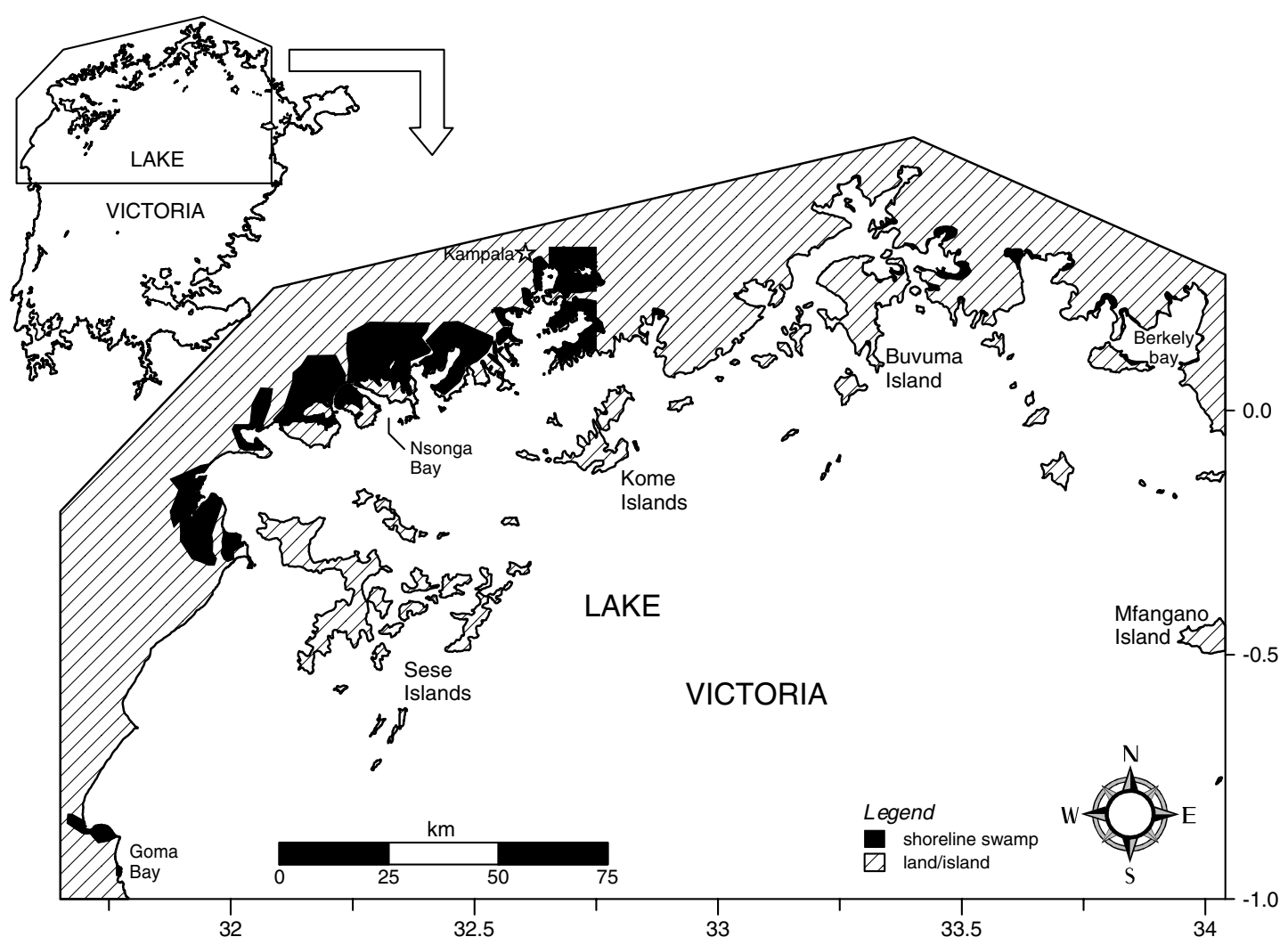

Figure 1. Map of the studied shore of Lake Victoria showing the location of large shoreline swamps. The swamps inhabit shores behind coastal islands or nest in the crooks of bay indentations. Map coordinates are in decimal degrees.

inspected and the location of vegetated areas noted in relation to coastal morphometric features and position of coastal islands. Wave exposure in vegetated and nonvegetated parts of shore was also measured and compared with the Mann-Whitney U-test. To generate points for the comparison, we conducted a ground-truthing survey of the shoreline by boat from 24-28 February 2003. During the survey, we marked the horizontal (alongshore) boundaries of fringe vegetation, both floating and bottomrooted, with a GPS. The survey, which covered $190 \mathrm{~km}$ of shore between Goma and Nsonga bays (Figure 1), was particularly important for locating non-swamp shoreline vegetation that normally occurs in bands too narrow to display on the available 1:50 000 topographic maps of the lake region. With the aid of the GPS coordinates, we marked the positions of identified bare and vegetated patches on topographic maps, and used the positions to compute wave exposure in the two types of shoreline following Equation 1.

\section{Variation of swamp area along a gradient of wave exposure}

The studied shore has a myriad of bays: some large, some small, some with and others without shoreline swamps. We selected 78 of the largest swamp-fringed bays for study. At three points across the mouth of each bay (one point at the far-left side of the bay, a second point at the far-right side of the bay and the third point midway between the other two points), we calculated maximum effective fetch and used the largest of the three values to represent wave exposure in the bay. Bay dimensions were extracted by planimeter from topographic maps. The area of swamp in each bay was determined from topographic maps and expressed as a fraction of total bay area. We used the resulting database on wave exposure and bay characteristics to investigate the variation of swamp area along a gradient of wave exposure through non-linear regression techniques.

\section{Influence of exposure and bay features on the limit of vegetation advancement}

The database was further used to assess, through hierarchical multiple linear regression, how well maximum effective fetch, fetch length variance, and the length, breadth, aspect ratio (i.e. ratio of bay width to breadth) and area of bays, predict the limit of lakeward vegetation 
advancement. Preliminary checks on data suitability and assumptions for multiple linear regression (independence of observations, normality, linearity, multicollinearity, homoscedasticity, singularity and absence of outliers) identified positive skew in the distribution of scores and strong correlation $(r>0.9)$ between some independent variables. To normalize score distribution, all (independent and dependent) variables were logarithmtransformed. To satisfy the assumption of multicollinearity, some independent variables (fetch length variance, bay length and bay breadth) were dropped and only three (wave exposure, bay area and aspect ratio) that were weakly correlated were retained for the regression analysis.

For quantification of the limit of lakeward vegetation advancement, an estimate was required of the distance of the forward edge of vegetation from the land/water boundary. We found difficulty in determining this distance as the highly irregular shape of most of Lake Victoria's bays creates a situation of multiple directions of vegetation advancement, leaving only the areas opposite the bay mouth under the direct influence of wind and waves from the open lake (cf. Figure 2). The problem was resolved by measuring the distance of the vegetation front relative to the bay mouth instead of the land/water boundary. For this purpose, we assumed waves to act by limiting vegetation advancement: then, high wave action at the bay mouth would halt the advancement of vegetation. In this context, other factors remaining favourable, the vegetation boundary signifies a point of dynamic equilibrium between vegetation growth and destruction by wind and waves.

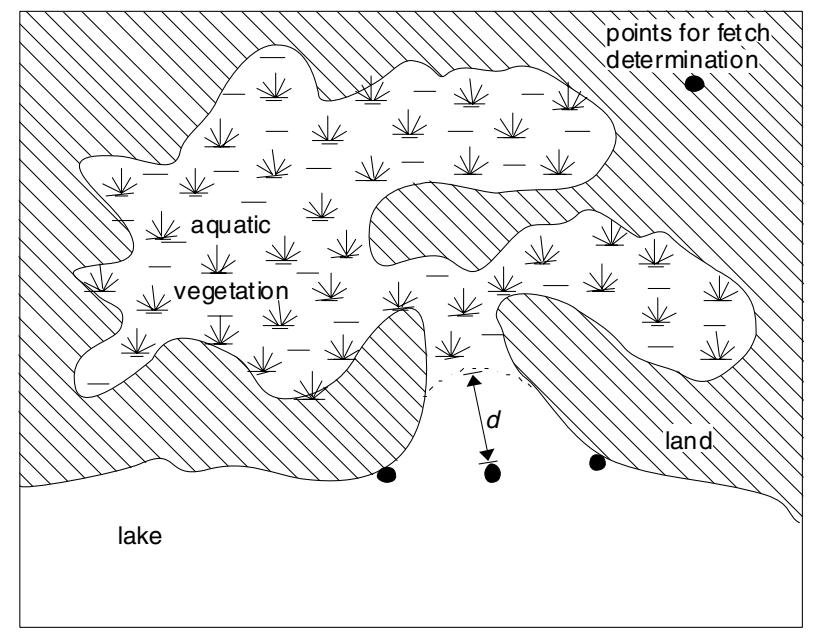

Figure 2. A hypothetical shoreline showing complex convolutions typical of the northern margins of Lake Victoria. The distance $d$ of the vegetation front from the bay mouth was used as a surrogate for the limit of lakeward vegetation advancement.

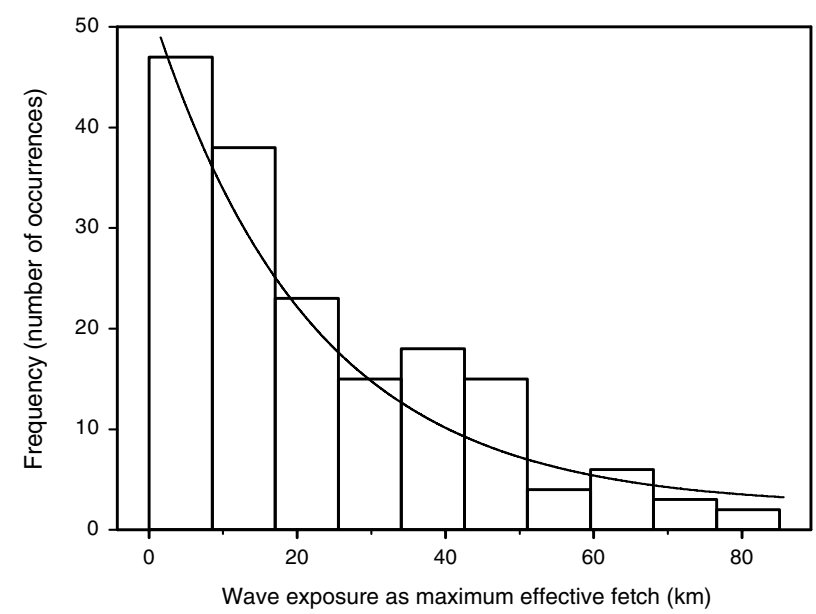

Figure 3. Histogram showing distribution of wave exposure in the sites occupied by shoreline vegetation. The curve represents a non-linear regression line fitted through the data. A bin range of $8.5 \mathrm{~km}$ (fetch) was used.

\section{RESULTS}

\section{Vegetation distribution along the shore}

The qualitative pattern of shoreline vegetation distribution on the northern coast of Lake Victoria suggests a strong influence of wave exposure on shoreline vegetation distribution. Shoreline plants, we noted, are not randomly distributed: they occur in locations where the action of wind and waves is lowest. These typically are stretches of shore behind coastal islands and in backwaters. We found wave exposure (determined as maximum effective fetch) in vegetated parts of the shore $(\mathrm{M}=23 \pm 1.48 \mathrm{~km})$ to be significantly lower than in bare shores $(\mathrm{M}=123 \pm 5.54 \mathrm{~km})$ (MannWhitney U-test, $\mathrm{z}=-12.2, \mathrm{P}<0.001)$. However, there was considerable overlap in the wave exposure range of vegetated and non-vegetated shores. Wave exposure in vegetated shores had a positively skewed distribution, with lower exposure values occurring more frequently than higher exposure values (Figure 3).

\section{Variation of swamp area along a gradient of wave exposure}

Our results show the fraction of bay area covered by swamps to decrease exponentially with increasing wave exposure. There appeared to be some clustering in the bays, which on scrutiny, seemed to arise from differences in the range of within-site variability in fetch length. In the application of Equation 1, fifteen values of fetch length $\left(x_{i}\right)$ are used to compute a single value of maximum effective fetch. Variability in fetch length can be small or large depending on the characteristics of the shoreline adjacent to the bay under consideration: it is small where 


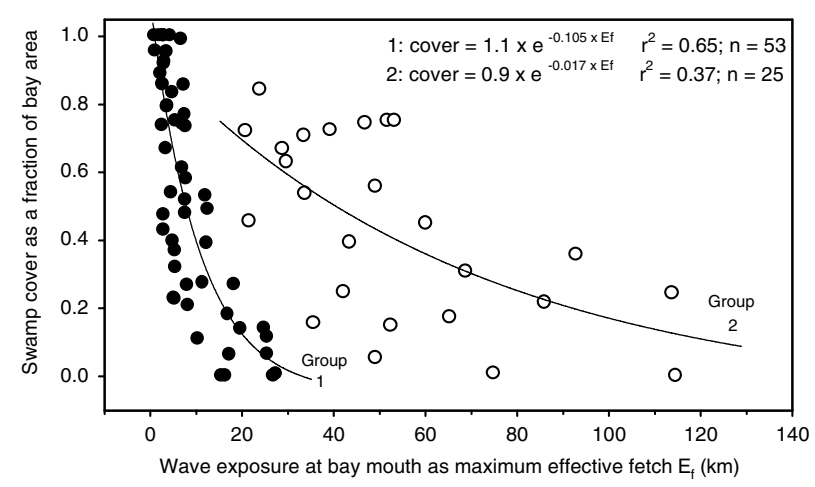

Figure 4. The relationship between swamp cover and wave exposure in bays. The 78 bays were subdivided into groups 1 and 2 using hierarchical cluster analysis based on four variables. For both regressions, $\mathrm{P}<0.005$.

the opposite shore is nearly straight; and large where the opposite shore is irregular, or where the presence of islands causes abrupt discontinuity in long fetches. To examine the apparent signs of some kind of grouping in the bays, we performed a hierarchical cluster analysis (between-groups linkage cluster method, Squared Euclidean distance measure, Z scores standardization) using the variables wave exposure, bay area, aspect ratio and limit of vegetation advancement. We obtained two groups, designated as groups 1 and 2, that differed in the exponential coefficients for swamp area decline (Figure 4). In group 1, zero swamp cover is approached around a wave exposure of $33 \mathrm{~km}$ while in group 2, it is reached above a wave exposure of $140 \mathrm{~km}$. Fetch length variance in group $1(\mathrm{M}=2.3 \pm 0.16 \mathrm{~km})$ was significantly lower than in group $2(\mathrm{M}=8.6 \pm 0.23 \mathrm{~km})(\mathrm{Mann}-$ Whitney U-test, $\mathrm{z}=-7.1 ; \mathrm{P}<0.0005)$. Other site features such as bay dimensions and swamp area were not significantly different for the two groups.

\section{Influence of exposure and bay features on the limit of vegetation advancement}

Wave exposure, in combination with bay area and bay aspect ratio, explained $64.4 \%$ of the variance in the lakeward limit of vegetation progression (Table 1). Wave exposure and bay area were strongly and positively correlated with the limit of vegetation progression, and made statistically unique contributions (beta $=0.346$ and 0.643 respectively) to the linear regression model (Table 2). The model as a whole was significant $\left(\mathrm{F}_{(2,75)}=67.9 ; \mathrm{P}<0.0005\right)$. The direction of the relationships obtained indicates that as wave exposure and bay area increase, the vegetation boundary recedes further and further away from baymouth into the bay. Bay aspect ratio was weakly correlated with the limit of vegetation advancement and, when included as a predictor, made no unique contribution to the model.
Table 1. Results of hierarchical multiple linear regression used to investigate the influence of wave exposure and coastal morphometric characteristics on the lakeward limit of vegetation progression. The column titled Sig. F Change shows the statistical significance associated with the change in $\mathrm{F}$ value.

\begin{tabular}{|c|c|c|c|c|c|}
\hline \multicolumn{2}{|r|}{ Model $^{\mathrm{a}}$} & \multirow[b]{2}{*}{$\mathrm{R}^{2}$} & \multirow{2}{*}{$\begin{array}{c}\mathrm{R}^{2} \\
\text { change }\end{array}$} & \multirow{2}{*}{$\begin{array}{c}\mathrm{F} \\
\text { change }\end{array}$} & \multirow{2}{*}{$\begin{array}{c}\text { Sig. F } \\
\text { change }\end{array}$} \\
\hline No. & Predictors & & & & \\
\hline 1. & $\begin{array}{l}\text { Constant, wave } \\
\text { exposure }\end{array}$ & 0.257 & 0.257 & 26.3 & $<0.001$ \\
\hline 2. & $\begin{array}{l}\text { Constant, wave } \\
\text { exposure, bay area }\end{array}$ & 0.644 & 0.387 & 81.6 & $<0.001$ \\
\hline
\end{tabular}

${ }^{\mathrm{a} D e p e n d e n t ~ v a r i a b l e: ~ l i m i t ~ o f ~ l a k e w a r d ~ v e g e t a t i o n ~ a d v a n c e m e n t . ~}$

Table 2. The coefficients for the final linear regression model. The column titled Standardized Coefficients Beta shows the regression coefficients for the model when all variables are expressed in standardized (z-score) form.

\begin{tabular}{llcrcc}
\hline & Model $^{\mathrm{a}}$ & & $\begin{array}{c}\text { Standardized } \\
\text { Coefficients } \\
\text { Beta }\end{array}$ & \multicolumn{1}{c}{$\mathrm{t}$} & \multicolumn{1}{c}{ Sig. } \\
\cline { 1 - 2 } No. & Predictors & & & -8.20 & $<0.001$ \\
\hline 2. & Constant & & 4.86 & $<0.001$ \\
& Wave exposure & & 0.346 & 9.03 & $<0.001$ \\
\hline
\end{tabular}

${ }^{\mathrm{a}}$ Dependent variable: limit of lakeward vegetation advancement.

\section{DISCUSSION}

\section{Wave exposure as a regulator of shoreline vegetation distribution}

This is the first quantitative demonstration of the applicability of the generalizations on the influence of wave exposure on shoreline vegetation distribution in a tropical lake. Our results reinforce and amplify the conception that wave exposure is a critical regulator of the within-lake distribution of vegetation, and shows wave-exposure to confine shoreline plants to the more sheltered sites on the coast, to cause an exponential decline in swamp area and, acting in combination with bay area, to limit the lakeward expansion of shoreline vegetation. Our findings further point to the existence of a (yet unknown) threshold wave exposure beyond which no plants occur. Below the threshold, plants are able to establish but they show a clear preference for low-exposure habitats as evidenced by the positively skewed frequency distribution of wave exposure in vegetated sites. The above findings are in accord with observations on the influence of wave exposure on temperate lake vegetation (Hudon et al. 2000, Keddy 1982, 1983; Pearsall 1920, Spence 1964, 1967). It was not possible from our data to ascertain whether or not the lack of distinct growing seasons of tropical systems makes vegetation more resilient to disturbance by wind and waves than temperate vegetation. While we have singled out the effect of wave exposure for this study, there are many regulating factors which must be looked at together for a complete explanation of the distribution of shoreline plants. 
Alternative explanations for the observed pattern of shoreline vegetation distribution are possible but less plausible than the action of wind and waves. The occupied sites might be more nutrient-rich than the unoccupied ones. Sediment deposition and resuspension, which are two of the processes responsible for producing variable substrate character and hence nutrient availability, are largely controlled by wind and wave action. Thus this explanation is an elucidation of the effect of wind and waves, rather than an alternative to it. Differences in geology and soil type may also produce variability in substrate characteristics. However, it is unnatural that nutrient-rich formations should only occur in embayments and behind islands.

Variable disturbance by man and animals could also lead to the observed pattern of shoreline vegetation distribution. However, the unfavourable physical environment of the shoreline wetlands (dense vegetation; boggy, unstable substrate; permanent inundation; mosquito and tsetse fly infestation) prohibits man and most large herbivores from entering the shoreline wetlands (Howard-Williams \& Gaudet 1985). A notable exception to the above generalization is the hippopotamus, which grazes on swamp vegetation and causes considerable damage to trampled plants by its enormous body weight. Low dissolved oxygen and $\mathrm{pH}$ values, which are prevalent in the interior of shoreline wetlands, contribute to the creation of an inhospitable environment and hinder many fish and other aquatic organisms from utilizing the interior of swamps. Thus, disturbance by man and animals may not be a significant contributor to the spatial distribution of shoreline vegetation.

Our results show a considerable overlap in the wave exposure range of bare and vegetated shores, which suggests that some habitable areas with respect to this disturbance are not colonized by vegetation. There are two possible reasons for this. The first is that the substrate in the uninhabited locations is not suitable for colonization by macrophytes. Spence (1967) from a study of Scottish lochs noted that shorelines comprised of boulders, coarse infertile gravels and highly reducing muds are rarely colonized by macrophytes. The second reason could be that the uninhabited locations have a high intensity or frequency of wave disturbance events. Further research is required to determine which of the two is the correct explanation.

\section{Feedbacks between wave exposure and vegetation distribution}

We have shown for the first time that embayment area has a strong influence on the lakeward expansion of shoreline vegetation. The lakeward vegetation boundary was located much further back from bay mouth in larger bays as compared with smaller bays. Since bay area is a primary determinant of the size of a bay's wind catchment, it is likely that the relationship obtained above is principally one between wave action and plant tolerance to this environmental control. It may be inferred from the relationship that in larger bays, a greater area of free-water surface is available for wave generation leading to correspondingly greater damage to plants.

If the above interpretation is correct, it implies that pioneer colonizers of a bay may facilitate secondary colonization through a feedback system: the presence of pioneer plants reduces the available surface for wave generation, leading to reduced wind-wave activity, which in turn makes it possible for more plants to establish in the area. This constitutes a previously unrecognized positive feedback in the establishment of floating mats of vegetation, and might be a potentially stabilizing mechanism for the development of an alternative vegetation state in lakes or embayments dominated by floating emergents (Scheffer et al. 2003). Although the study emphasizes that this relationship is likely complex, it is conceivable that feedback mechanisms of this nature play a role in the filling of bays by vegetation. Research to further examine feedbacks between wave exposure and plant establishment is recommended.

\section{Disturbance intensity versus disturbance frequency}

The difference that we noted in the rate of swamp area decline in bays of differing fetch length variance suggests that it is not the maximal wave disturbance event in a year, but rather the overall stress levels caused by wave disturbance throughout the year, that have the greatest influence on shoreline vegetation development. In bays with small variance in fetch length, for a given wind speed, waves of about the same energy are generated from all compass directions used in effective fetch computation. On the other hand, in bays with large variance in fetch length, there are directions from which low-energy waves are generated as well as directions from which high-energy waves are generated. The resulting intermittent nature of strong wave action in the latter type of bays (assuming that winds are of variable direction during the year) may allow for periods of repair and recovery in between large disturbance events and produce the observed slower decline in vegetation cover with increasing wave exposure. Thus while surrogates of wave exposure like maximum effective fetch provide a simple and rapid means of estimating the magnitude of wave exposure, the results suggest that reliance on a measure of wave disturbance intensity without consideration for the disturbance frequency may lead to under- or overestimation of the impact of the disturbance. This is especially so where there is a fairly even distribution of 
windy days in the calendar year. Coops et al. (1991) came to a similar conclusion when studying the direct and indirect effects of wave action on shoreline vegetation.

Wave exposure proxies, such as used in this study, are being increasingly applied in combination with other environmental variables like water depth, underwater light intensity, substrate type, hydrological regime and disturbance, to explain and predict the spatial distribution of aquatic vegetation in lakes. From the foregoing discussion, the predictive ability of the approaches could be enhanced by taking into account not only the magnitude but also frequency of wave disturbance events, as illustrated for example by Keddy (1982).

We were unable to incorporate measures of wind duration in the computation of wave exposure due to data limitations. In the study area there is only one meteorological station, located at Entebbe International Airport, that measures hourly wind speed and direction. However, conditions at this single site could not be taken to be representative of conditions along the entire $675-\mathrm{km}$ stretch of shore with its large variability in aspect, local topography and coastal morphometry.

\section{ACKNOWLEDGEMENTS}

We thank the Lake Victoria Environmental Management Project (LVEMP) in Uganda for funding the study, and Festus Rusoona for assisting with cartographic work and fetch measurements.

\section{LITERATURE CITED}

CARPENTER, S. R. 1983. Submersed macrophyte community strata and internal loading: relationship of lake ecosystem production and succession. Lake and Reservoir Management 2:105111.

CERC (COASTAL ENGINEERING RESEARCH CENTRE) 1984. Shore protection manual. U.S. Army Corps of Engineers, Fort Belvoir, Virginia. 603 pp.

CHAMBERS, P. A. 1987. Nearshore occurrence of submersed aquatic macrophytes in relation to wave action. Canadian Journal of Fisheries and Aquatic Science 44:1666-1669.

COOPS, H., BOETERS, R. \& SMIT, H. 1991. Direct and indirect effects of wave attack on helophytes. Aquatic Botany 41:333-352.

COOPS, H., GEILEN, N. \& VAN DER VELDE, G. 1994. Distribution and growth of the helophyte species Phragmites australis and Scirpus lacustris in water depth gradients in relation to wave exposure. Aquatic Botany 48:273-284.

CRUL, R. C. M. 1998. Management and conservation of the African Great Lakes. UNESCO, Paris. 107 pp.

DENNY, P. 1973. Lakes of South-western Uganda II: vegetation studies on Lake Bunyonyi. Freshwater Biology 3:123-135.
DENNY, P. 1985a. The structure and functioning of African euhydrophyte communities: the floating-leaved and submerged vegetation. Pp. 125-152 in Denny P. (ed.). The ecology and management of African wetland vegetation. Dr. W. Junk Publishers, Dordrecht.

DENNY, P. 1985b. Submerged and floating-leaved aquatic macrophytes (euhydrophytes). Pp. 19-42 in Denny P. (ed.). The ecology and management of African wetland vegetation. Dr. W. Junk Publishers, Dordrecht.

DENNY, P. 1985c. Wetland vegetation and associated life forms. Pp. 1-18 in Denny P. (ed.). The ecology and management of African wetland vegetation. Dr. W. Junk Publishers, Dordrecht.

DENNY, P. 1993. Eastern Africa. Pp. 32-46 in Whigham, D. F., Dykyjová, D. \& Hejný, S. (eds.). Wetlands of the world. I. Kluwer Academic Publishers, Dordrecht. 768 pp.

DUARTE, C. M. \& KALFF, J. 1986. Littoral slope as a predictor of the maximum biomass of submerged macrophyte communities. Limnology and Oceanography 31:1072-1080.

FOOTE, A. L. \& KADLEC, J. A. 1988. Effects of wave energy on plant establishment in shallow lacustrine wetlands. Journal of Freshwater Ecology 4:523-532.

HÅKANSON, L. \& JANSSON, M. 1983. Principles of lake sedimentology. Springer-Verlag, Berlin. 316 pp.

HOWARD-WILLIAMS, C. \& GAUDET, J. J. 1985. The structure and functioning of African swamps. Pp. 153-176 in Denny P. (ed.). The ecology and management of African wetland vegetation. Dr. W. Junk Publishers, Dordrecht.

HUDON, C., LALONDE, S. \& GAGNON, P. 2000. Ranking the effects of site exposure, plant growth form, water depth and transparency on aquatic plant biomasses. Canadian Journal of Fisheries and Aquatic Science 57:31-42.

HUTCHINSON, G. E. 1975. A treatise on limnology. John Wiley and Sons, New York. 660 pp

KEDDY, P. A. 1982. Quantifying within-lake gradients of wave energy: interrelationships of wave energy, substrate particle size and shoreline plants in Axe Lake, Ontario. Aquatic Botany 14:4158.

KEDDY, P. A. 1983. Shoreline vegetation in Axe Lake, Ontario: effects of exposure on zonation patterns. Ecology 64:331-344.

KEDDY, P. A. 2000. Wetlands - principles and conservation. Cambridge University Press, Cambridge. 614 pp.

KENNEDY, C. W. \& BRUNO, J. F. 2000. Restriction of the upper distribution of New England cobble beach plants by wave-related disturbance. Journal of Ecology 88:856-868.

LIND, E. M. \& MORRISON, E. S. 1974. East African vegetation. Longman Group, London. 257 pp.

LVEMP (LAKE VICTORIA ENVIRONMENTAL MANAGEMENT PROJECT). 2002. The Lake Victoria integrated water quality and limnology study. Dar-es-Salaam, Tanzania, LVEMP Regional Secretariat. $162 \mathrm{pp}$.

MAAS, L. R. M., BENIELLI, D., SOMMERIA, J. \& LAM, F.-P. A. 1997. Observation of an internal wave attractor in a confined stably stratified fluid. Nature 388:557-561.

PEARSALL, W. H. 1920. The aquatic vegetation of the English Lakes. Journal of Ecology 8:163-201. 
RIIS, T. \& HAWES, I. 2003. Effects of wave exposure on vegetation abundance, richness and depth distribution of shallow water plants in a New Zealand lake. Freshwater Biology 48:7587.

SCHEFFER, M., SZABO, S., GRAGNANI, A., VAN NES, E. H., RINALDI, S., KAUTSKY, N., NORBERG, J., ROIJACKERS, R. M. M. \& FRANKEN, R. J. M. 2003. Floating plant dominance as a stable state. Ecology 100:4040-4045.
SPENCE, D. H. N. 1964. The macroscopic vegetation of freshwater lochs, swamps and associated fens. Pp. 305-345 in Burnett J. H. (ed.). The vegetation of Scotland. Oliver and Boyd, Edinburgh and London.

SPENCE,D.H.N. 1967. Factors controlling the distribution of freshwater macrophytes with particular reference to the lochs of Scotland. Journal of Ecology 55:147-170.

SPENCE, D. H. N. 1982. The zonation of plants in freshwater lakes. Advances in Ecological Research 12:37-125. 